\title{
ANÁLISE ESPAÇO TEMPORAL DA EVAPOTRANSPIRAÇÃO SOBRE A MICRORREGIÃO DO SERIDÓ NO ESTADO DO RIO GRANDE DO NORTE
}

\author{
Edmir dos Santos Jesus ${ }^{1}$ e Arthur Mattos ${ }^{2}$ \\ Universidade Federal do Rio Grande do Norte \\ E-mail: edmir.jesus@gmail.com ${ }^{1}$; armattos@ct.ufrn.br ${ }^{2}$
}

Artigo submetido em outubro/2013 e aceito em dezembro/2013

\section{RESUMO}

Este estudo teve como objetivo estimar as evapotranspirações potencial e real de área dos municípios pertencentes a microrregião do Seridó no Estado do Rio Grande do Norte, utilizando do modelo complementar de Morton. Após isso procurouseespacializar os resultados para verificar como se distribui a ETR e ETP sobre a região. Pela análise feita ficou evidente que nas regiões onde a primeira é alta a outra tende a ser baixa. Foi visto que a ETR correspondeu a valores baixos na porção central e a altos no extremo norte e sul da microrregião do Seridó tal como a ETP. Relacionando com a disponibilidade de energia concluiu-se que durante o ano essa variáve fosse mais importante no processo de evapotranspiração do que a precipitação sobre o Seridó, tornando o Modelo adequado para avaliar quando houver a baixa na precipitação.

PALAVRAS-CHAVE: evapotranspiração; precipitação; disponibilidade hídrica.

\section{ANALYSIS OF SPACE TIME ESTIMATE EVAPOTRANSPIRATION ON THE MICRORREGION OF SERIDÓ IN THE RIO GRANDE DO NORTE STATE}

\begin{abstract}
This study objective to estimate the potential evapotranspiration and actual area of the municipalities belonging to the micro Seridó in the state of Rio Grande of the North, using the complementary model of Morton. After that we tried to spatialize the results to see how it distributes the ETR and ETP on the region. For the analysis it became clear that in regions where the first one is high the other tends to be low. It was seen
\end{abstract}

that the ETR corresponded to low values in the central and high in the extreme north and south of micro Serido as the ETP. Relating to the availability of energy concluded that during the year this variable was more important in the process of evaporation than precipitation on Seridó, making the model suitable for assessing when there low in precipitation.

KEYWORDS: evapotranspiration; precipitation; hidric availability. 


\section{ANÁLISE ESPAÇO TEMPORAL DA EVAPOTRANSPIRAÇÃO SOBRE A MICRORREGIÃO DO SERIDÓ NO ESTADO DO RIO GRANDE DO NORTE}

\section{INTRODUÇÃO}

Como uma das mais importantes variáveis no ciclo hidrológico, a evapotranspiração refere-se a perda conjunta d'água para a atmosfera que sob condições de restrições hídricas, constitui um processo muito complexo e de difícil dedução por métodos climatológicos. Sob estas condições, o estado da água disponível ao ambiente radicular das plantas cultivadas e na superfície do solo, afeta significativamente a razão de evapotranspiração (MOTA,1977).

No Estado do Rio Grande do Norte, o Seridó é uma das microrregiões que abrange dezessete municípios, o qual possui área de aproximadamente $9.372 \mathrm{~km}^{2}$, correspondendo a quase $18 \%$ do Estado, com uma população estimada de 260.000 habitantes (IBGE, 2000). Esta região está inserida na área semiárida da Região Nordeste do Brasil (NEB), com regime pluviométrico bastante irregular tanto espacialmente como temporalmente. A atividade econômica principal do Seridó é a agropecuária. Entretanto, a falta de água no solo torna-se a principal limitação para o pequeno agricultor, não apenas pelo seu volume total anual de precipitação pluvial, mas pela distribuição irregular. Este fato reforça a necessidade de um monitoramento contínuo hidrológico da microrregião do Seridó. Esse tipo de informação terminada é de extrema necessidade para diversos fins na agricultura, prevenção de incêndios florestais e o planejamento de consumo de água nas grandes comunidades (ISAIAS et al. 1992).

Segundo Bezerra Júnior \& Souza (2007), o clima semi-árido com suas altas temperaturas, baixas médias pluviométricas, dentre outras características influenciam o sistema hidrográfico. Devido ao déficit hídrico intenso, a região seridoense abriga inúmeras barragens que trazem oportunidades para prática de irrigação, uso humano e turístico no intuito de diminuir as dificuldades socioeconômicas que se apresentam na época da seca.

Em regiões semiáridas o déficit observado no balanço hídrico anual constitui um grave problema as atividades agropecuárias, pois a deficiência hídrica limita à produção agrícola, diminui a disponibilidade de água para dessedentação animal e consumo humano, sendo assim fonte de risco agrícola nestas áreas. Desta forma a quantificação da evapotranspiração assume particular acepção em virtude destes eventos de déficit hídrico, ajudando no planejamento agrícola, indicando o período de escassez de água e assim buscando-se formas de as culturas para que não haja perda da agrícola (MENDONÇA \& DANTAS, 2010).

Devido à dificuldade de se estimar a evapotranspiração diversos modelos empíricos são encontrados na literatura, os quais respondem e que levam em consideração as variáveis climáticas reinantes da região de estudo. Dessa forma, BOUCHET (1963) formulou a hipótese de que variações nas evapotranspirações potencial e real de área, devido à variações no fornecimento de umidade regional são complementares. MORTON (1965) desenvolveu uma equação para a hipótese de Bouchet, a qual foi sendo aperfeiçoada pelo mesmo até chegar no modelo de relação complementar. Este modelo está fundamentado no conceito de que existe uma relação complementar entre a evapotranspiração potencial e a evapotranspiração real de 
área, isto é, existe uma resposta complementar, igual e de sinal contrário entre ambas, devido as mudanças de disponibilidade de água para a evapotranspiração real de área.

Alguns autores como (JESUS \& ASSIS, 2004), GOSSON (2005), JESUS et al. (2012) mostram que a utilização do modelo de relação complementar de Morton para a obtenção da evapotranspiração potencial e evapotranspiração real de área obteve bons resultados comparados aos dados observados. Neste sentido, este trabalho teve como objetivo analisar a estimativa das evapotranspirações potencial e real de área sobre os municípios localizados na microrregião do Seridó.

\section{MATERIAL E MÉTODOS}

\section{1 Área de estudo}

A região de estudo abrange a microrregião do Seridó no Estado do Rio Grande do Norte, situada entre os paralelos de $6^{\circ} 06^{\prime}$ e $6^{\circ} 55^{\prime}$ Sul e meridianos de $37^{\circ} 25^{\prime}$ e $36^{\circ} 22^{\prime}$ Oeste com altitudes entre 134 a 572 metros (Figura 1). Segundo a classificação climática de Thornthwaite, o clima desta região é $D_{d A}{ }^{\prime} a^{\prime}$, ou seja, semi-árido, megatérmico, com excedente hídrico pequeno ou nulo e concentração da evapotranspiração nos meses de verão igual a $26 \%$, atingindo uma média anual de $1.464 \mathrm{~mm}$.

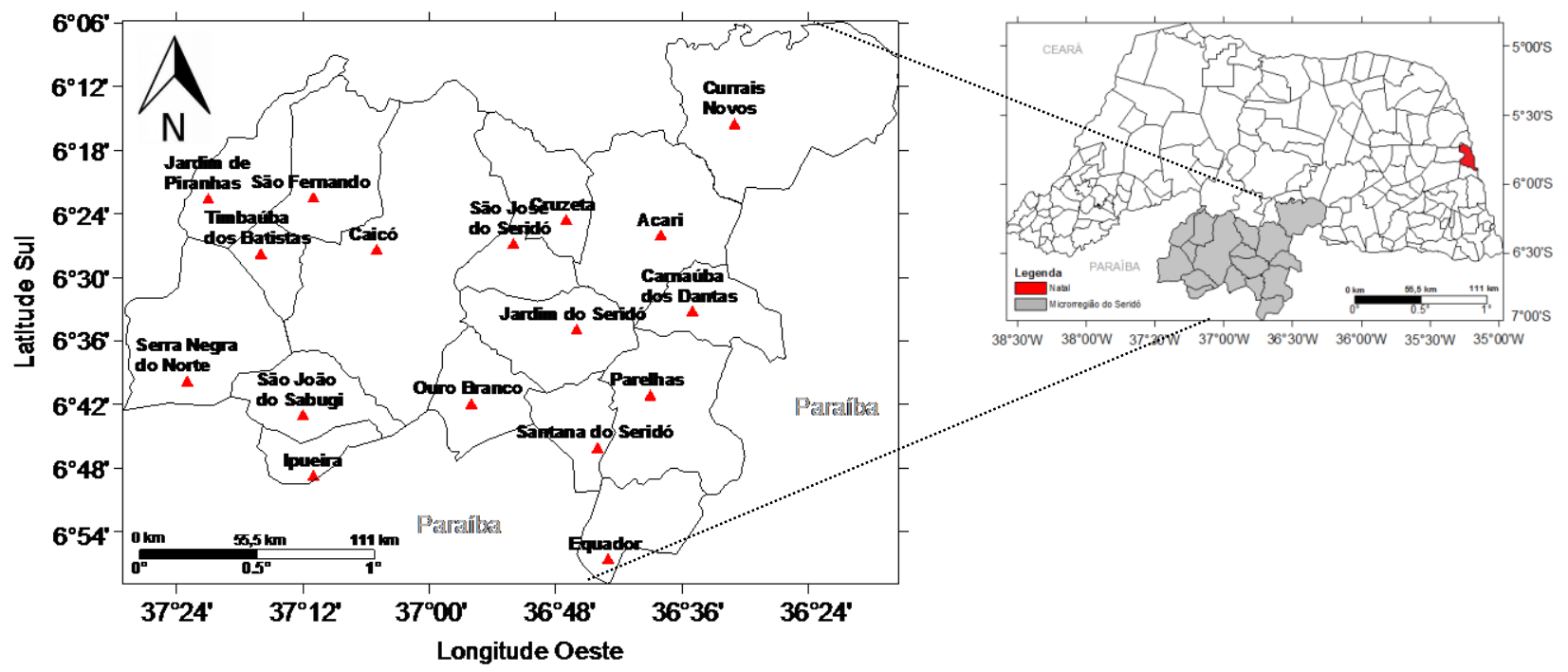

FIGURA 1. Localização geográfica dos municípios na microrregião do Seridó. (Fonte: do Autor)

\subsection{Dados meteorológicos utilizados}

Para a realização deste trabalho foram selecionados os dados meteorológicos mensais dos dezessete municípios como a temperatura do $\operatorname{ar}\left({ }^{\circ} \mathrm{C}\right)$, umidade relativa do ar $(\%)$, insolação (horas), temperatura do ponto de orvalho $\left({ }^{\circ} \mathrm{C}\right)$, pressão real $(\mathrm{mb})$ e de saturação do vapor $(\mathrm{mb})$ e total anual de precipitação $(\mathrm{mm})$. A série de dados foi obtida de estações meteorológicas de superfície monitoradas pelo 3 DISME (Distrito de Meteorologia) e pela Empresa de Pesquisa Agropecuária do Rio Grande do Norte (EMPARN)que correspondem ao período de 1963 a 2008. 
Os dados climatológicos de temperatura média do ar foram estimados em cada município da microrregião por meio do softwareEstima_T (Cavalcanti et al. 2006), do Departamento de Ciências Atmosféricas (DCA), da Universidade Federal de Campina Grande (UFCG). Estes dados estimados de temperatura do ar levam em consideração uma série temporal de 30 anos (1961 a 1990) através das estações meteorológicas convencionais instaladas no Rio Grande do Norte pelo Instituto Nacional de Meteorologia (INMET).

Para estimar as evapotranspirações potencial e real de área, foi utilizado o programa computacional WREVAP, desenvolvido em linguagem Fortran, desenvolvido por MORTON et al. 1985. Este programa possui três opções: modelo CRAE (relação complementar de evapotranspiração de área), modelo CRWE (relação complementar de evaporação de superfície saturada) e modelo CRLE (relação complementar de evaporação de lago). A opção de programa WREVAP utilizada neste trabalho foi o modelo CRAE.

O programa WREVAP foi desenvolvido para ter como valores de entrada osdados climatológicos medidos para um período que varia de um dia a um mês. Os dados meteorológicos utilizados para inicializaro modelo CRAE, foram: médias mensais de temperatura do ponto de orvalho $\left({ }^{\circ} \mathrm{C}\right)$, da temperatura do $\operatorname{ar}\left({ }^{\circ} \mathrm{C}\right)$, da insolação real (horas) e normal anual de precipitação $(\mathrm{mm})$; além da altitude $(\mathrm{m})$ e latitude (graus) da estação meteorológica. Obtendo como valores de saída a ETP (evapotranspiração potencial), ETR (evapotranspiração real), e Rn (saldo de radiação solar).

A base conceitual do modelo CRAE leva em consideração os efeitos de fenômenos de Larga Escala que contribuem para variar a taxa de evapotranspiração e a equação que descreve a relação complementar, segundo MORTON (1983), é expressa da seguinte forma:

$$
E T_{P}=2 E T_{W}-E T_{R}
$$

onde : $E T_{P}$ é a evapotranspiração potencial que é estimada de uma solução de equações do balanço de energia e do transporte de vapor d'água, representando a evapotranspiração que ocorreria em uma superfície úmida hipotética, com características de absorção de radiação e de transporte de vapor semelhantes àquelas de uma extensa área; $E T_{R}$ é a evapotranspiração real de área que ocorre em uma área bastante extensa e $E T_{W}$ representa a evapotranspiração de um ambiente úmido. A Figura 2 mostra a relação esquemática entre as três variáveis da Equação (1), considerando o fornecimento de energia radiante constante.

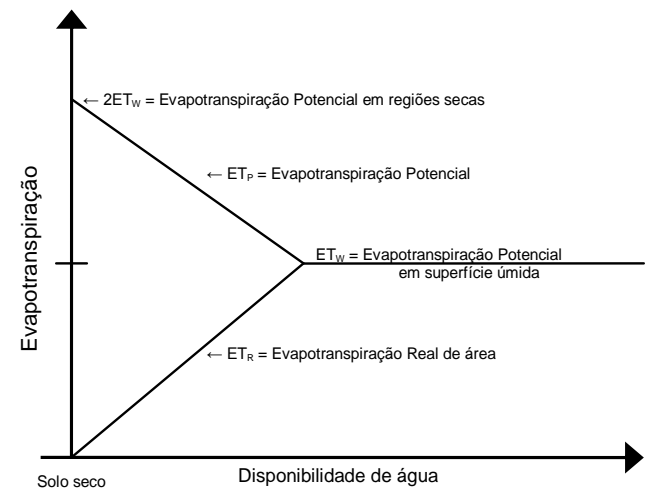

FIGURA 2. Representação esquemática da relação complementar entre evapotranspiração potencial e evapotranspiração real de área, com fornecimento de energia radiante constante (MORTON, 1983). Fonte: Adaptação PEREIRA (1997). 
A ordenada representa a evapotranspiração e a abscissa representa o fornecimento de água às superfícies solo-planta da área, uma quantidade que é normalmente desconhecida. Quando não existe água disponível para a evapotranspiração real de área (extremo esquerdo da Figura 2) a $E T_{R}$ é igual a zero, e o ar é muito quente e seco. $E T_{P}$ tem valor máximo que é igual a $2 E T_{W}$. Quando o fornecimento de água para as superfícies solo-planta aumenta, o aumento equivalente resultante em $E T_{R}$ modifica as condições do ar que está circulando sobre a região, tornando-o mais frio e mais úmido, o qual, em retorno (feedback), produz um decréscimo equivalente em $E T_{P}$. Finalmente, quando o fornecimento de água para as superfícies solo-planta da área aumenta suficientemente, os valores de $E T_{R}$ e $E T_{P}$ convergem para $E T_{W}$.

No modelo de Morton, a $E T_{P}$ é estimada de uma solução de equações do balanço de energia (Equação 2) e saldo de radiação à temperatura de equilíbrio $R_{N p}$ (Equação 3)proposta por Priestley-Taylor (1972), ajustada para levar em conta os efeitos de advecção (divergência horizontal) de Larga Escala.

$$
\begin{aligned}
& E T_{P}=R_{N}-f_{T}\left[\gamma p+\frac{4 \varepsilon \sigma}{f_{T}}(T+273)^{3}\right]\left(T_{p}-T\right) \\
& R_{N p}=E T_{P}+\gamma p f_{T}\left(T_{p}-T\right)
\end{aligned}
$$

em que $T_{p}$ é a temperatura de equilíbrio $\left({ }^{\circ} \mathrm{C}\right), T$ é a temperatura do $\operatorname{ar}\left({ }^{\circ} \mathrm{C}\right), f_{T}$ é o coeficiente de transferência de vapor d'água, $\lambda$ é o coeficiente de transferência de calor $\left(2,45 \mathrm{MJ} \mathrm{kg}^{-1}\right)$, sendo $\gamma$ a constante psicrométrica $\left(\mathrm{kPa}^{\circ} \mathrm{C}^{-1}\right), p$ é a pressão atmosférica $(\mathrm{kPa}), \sigma$ é a constante de Stefan-Boltzman $\left(4,8989 \times 10^{-9} \mathrm{MJ} \cdot \mathrm{m}^{-2} \cdot \mathrm{K}^{-4} \cdot \mathrm{dia}^{-1}\right)$, e $\varepsilon$ a emissividade da superfície.

A estimativa do saldo de radiação $\left(R_{n}\right)$ para superfície solo-planta à temperatura do $\operatorname{ar}(T$ ), envolve as variáveis: albedo médio $(\alpha)$;albedo médio a céu claro $\left(\alpha_{0}\right)$;radiação solar global ( $R_{g}$ ) e perda de radiação de onda longa para o conjunto solo-planta $\left(R_{o l}\right)$, conforme descrito as Equações:

$$
R_{n}=(1-\alpha) R_{g}-R_{o l}
$$

com as contribuições :

$$
\begin{aligned}
& \alpha=\alpha_{0}\left[\frac{n}{N}+\left(1-\frac{n}{N}\right)\left(1-\frac{Z}{330}\right)\right] \\
& R_{g}=\mathrm{R}_{\mathrm{g} 0} \cdot \frac{n}{N}+\left(0,08+0,30 \cdot \frac{n}{N}\right)\left(1-\frac{n}{N}\right) R_{o}
\end{aligned}
$$


$R_{o l}=\varepsilon \sigma(T+273)^{4}\left[1-\left(0,71+0,007 e_{s} \cdot \frac{p}{p_{s}}\right)(1+\rho)\right]$

$R_{g_{0}}=R_{o} \cdot \tau\left[1+\left(1-\frac{\tau}{\tau_{a}}\right)\left(1+a_{0} \cdot \tau\right)\right]$

$R_{0}=\left(\frac{1354}{\eta^{2}}\right)\left(\frac{\omega}{180}\right) \cos Z$

onde : $R_{g_{0}}$ é a radiação global $\left(\mathrm{MJ} \cdot \mathrm{m}^{-2} \cdot \mathrm{d}^{-1}\right)$ a céu claro; $R_{0}$ é a irradiância solar $\left(\mathrm{MJ} \cdot \mathrm{m}^{-2} \mathrm{~d}^{-1}\right)$ no topo da atmosfera; $\eta$ é a excentricidade da órbita da Terra em torno do Sol; $\frac{n}{N}$ é a razão de insolação; $e_{s}$ é a pressão de saturação de vapor $(\mathrm{mb})$ à temperatura do ponto de orvalho $T_{d}$ em $\left({ }^{\circ} \mathrm{C}\right) ; \frac{p}{p_{s}}$ é a razão da pressão atmosférica na estação pela pressão ao nível do mar com a correção da pressão para atmosfera padrão; $\frac{\tau}{\tau_{a}}$ é a razão de transmitância a céu claro pela fração absorvida; $\omega$ é o ângulo horário, $Z$ é o ângulo zenital ao meio dia.

\section{RESULTADOS E DISCUSSÃO}

3.1 Análise anual da evapotranspiração real de área e potencial em função da precipitação, saldo de radiação, temperatura, umidade relativa e insolação.

$\mathrm{Na}$ discussão dos resultados destacamos as Figuras $3 a$ e $3 b$, onde tem-se a distribuição espacial da evapotranspiração real e potencial anual para a microrregião do Seridó, e neste, observa-se que os menores valores de ETP foram registrados na região nordeste e leste do Seridó. Segundo Ross (2003) essa região é formada pela Depressão Sertaneja e pelo Planalto da Borborema favorecendo a menor demanda hídrica pelas plantas através da evapotranspiração, devido a alguns condicionantes climáticos, que segundo Pereira et al.(2002) o efeito combinado de temperatura, umidade relativa e velocidade do vento define a demanda atmosférica por vapor d'águaem cada região. Os maiores valores registrados da evapotranspiração foram observados nas regiões oeste e centro-oeste da microrregião do Estado.

Analisando a distribuição espacial da ETR (Figura 3a), verifica-se o aumento gradativo do centro-oeste do Seridó ocidental ao norte e sudeste da microrregião. Em parte das localidades de Timbaúba dos Batistas, Caicó, São João do Sabugi e Jardim do Seridó seu valor foi superior a $1.120 \mathrm{~mm}$. Ainda pode ser visto que os menores valores de ETR estiveram concentrados na porção da região centro-oeste, como em Caicó $(1.111,4 \mathrm{~mm})$ e São João do Sabugi $(1.123,6 \mathrm{~mm})$ e na região extremo nordeste, como em Currais Novos $(1.291,1 \mathrm{~mm})$ os quais demonstram superestimados comparados aos valores encontrados por Gosson (2005).

A Figura 3b mostra a distribuição da ETP, onde se observa o aumento da variável na direção oeste do Seridó, com valores de 2.300 a $2.500 \mathrm{~mm}$, principalmente nas localidades de 
Jardim de Piranhas, São Fernando, Timbaúba dos Batistas, Serra Negra do Norte, Caicó e Ipueira $(2.520,4 \mathrm{~mm})$. Osmenores valores concentraram-se na região nordeste, como em Currais Novos e numa pequena faixa ao sul com valores abaixo de $2.200 \mathrm{~mm}$. Dado aos fatores do saldo de radiação, superior a $4.300 \mathrm{MJ} \cdot \mathrm{m}^{-2} \cdot \mathrm{dia}^{-1}$ (Figura 4c), da insolação, entre 2.800 e 2.900 horas (Figura 4d) da alta temperatura em torno de $27^{\circ} \mathrm{C}$ (Figura 4a) e a baixa na umidade relativa do ar (em torno de $60 \%$, Figura $4 \mathrm{~b}$ ) que somadas ocasionam a alta taxa de evapotranspiração em toda a microrregião.

Como a relação complementar de Morton entre a evapotranspiração potencial e real de área é baseada na interação entre a superfície evaporante e o ar ambiente, quando ocorre uma redução na disponibilidade de água para a evapotranspiração real de área, o ar torna-se mais quente e mais seco, o que causa o aumento da evapotranspiração potencial. Por isso, é que nas regiões onde a ETR é baixa, a ETP é alta, e há restrições na disponibilidade de água que é representada pela precipitação (Figura $3 \mathrm{c}$ ).

Ressalta-se que em Caicó, na porção central, a ETR foi bem abaixo da ETP, com uma diferença em torno de $1.439,9 \mathrm{~mm}$. A precipitação (Figura 3c) observada ficou acima de $700 \mathrm{~mm}$, mas a alta demanda evaporativa para a atmosfera foi influenciada por temperaturas médias elevadas associada com a disponibilidade de energia (Figura 4c).

Ainda segundo Santos et al. (2010) que calcularam o balanço hídrico climatológico para a microrregião do Seridó pelo método de Thornthwaite e Mather (1955) verificaram as variabilidades sazonais conforme a evapotranspiração potencial e real e viram que a deficiência hídrica é bastante elevada na região, concentrando-se no período de junho a dezembro, não ocorrendo excedente em nenhum outro mês. Comparando os valores encontrados pelos métodos na região, vimos os estimados pelo método de Morton superestimaram os valores encontrados por Thornthwaite e Matter.

Ao verificar os valores de ETR, ETP e PRP percebe-se o quanto há de perda de água em toda a microrregião tornando a região em completa escassez comprometendo a toda a população do Seridó, confirmando o levantamento feito por Bezerra Junior e Silva (2007). 

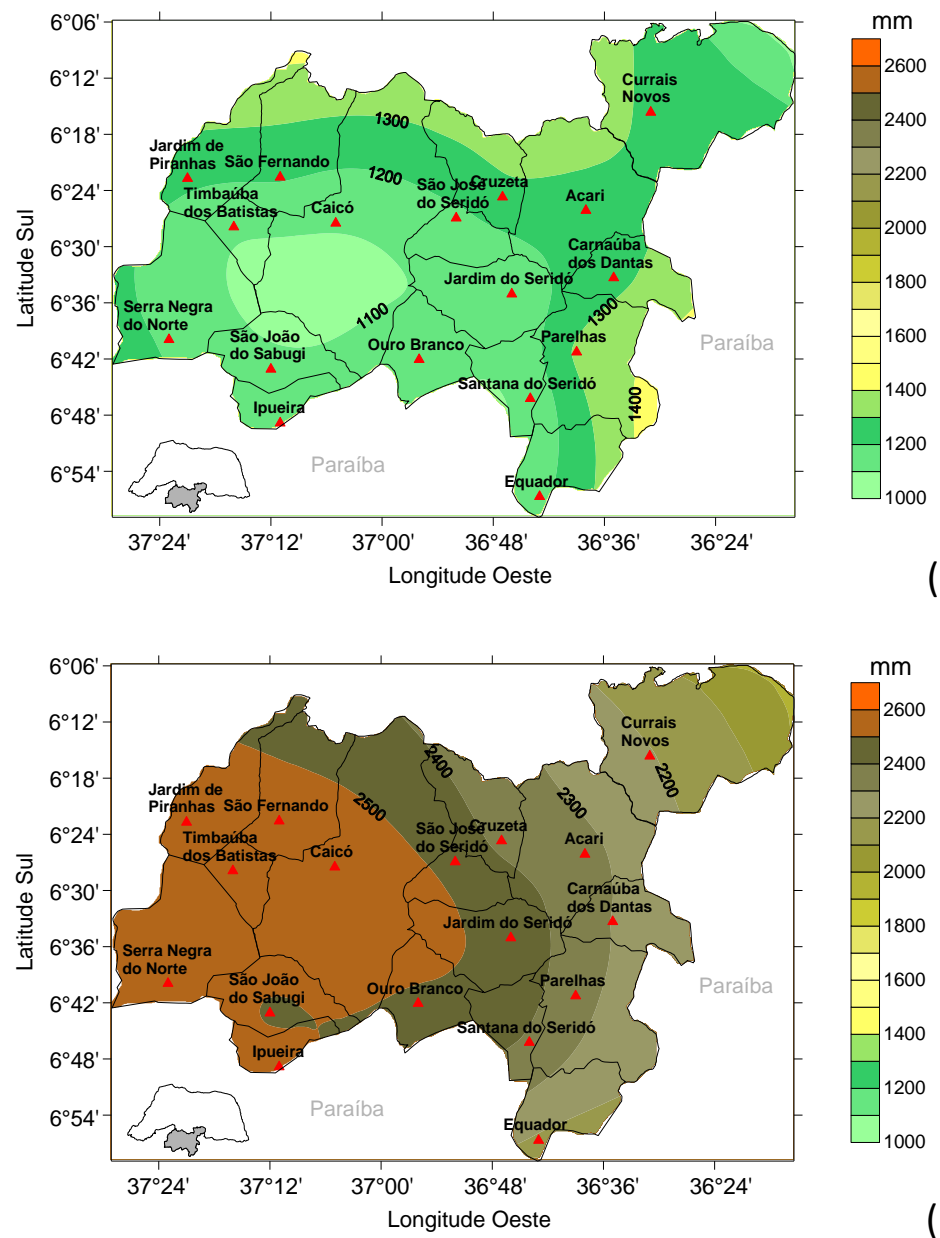

(a)
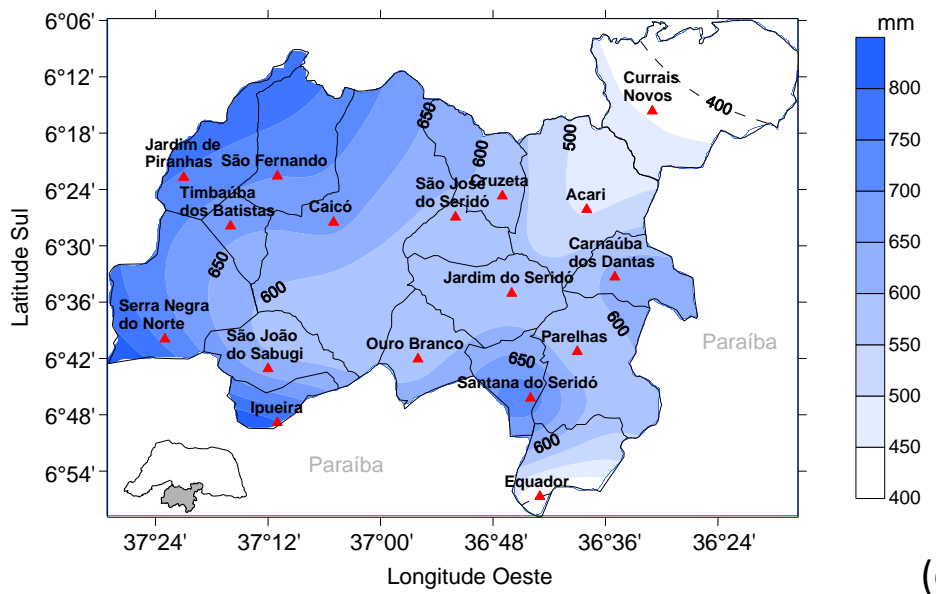

FIGURA 3. Distribuição espacial do total anual da Evapotranspiração Real de Área(a), Evapotranspiração Potencial (b) e Precipitação (c). 

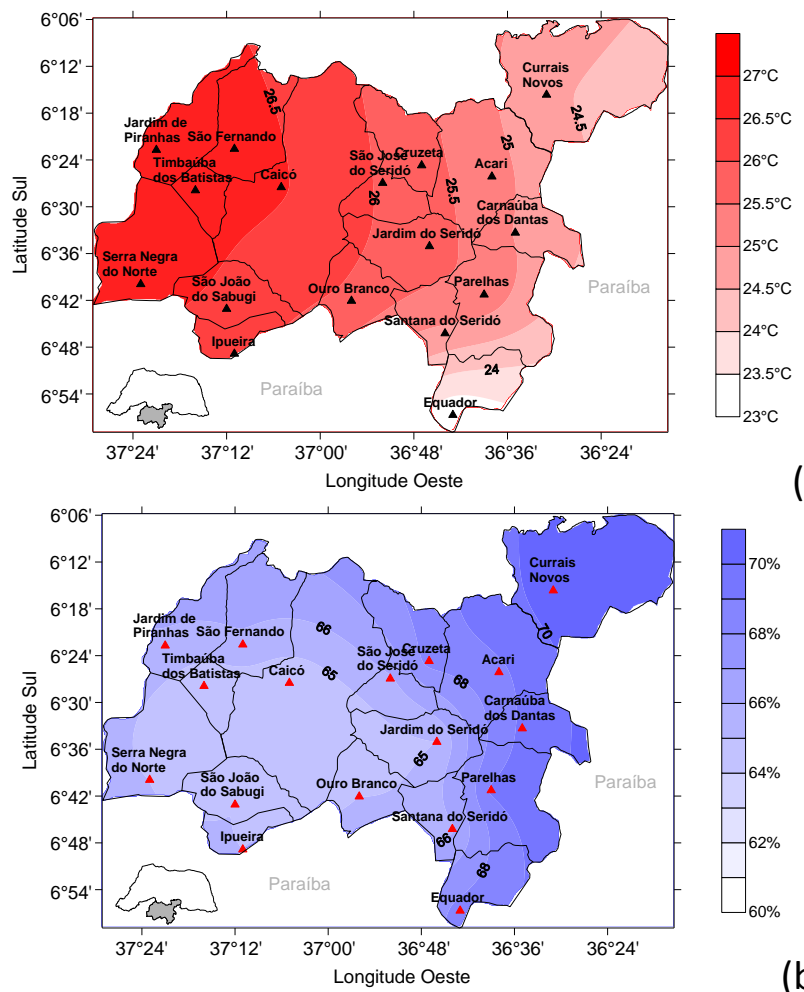

(a)

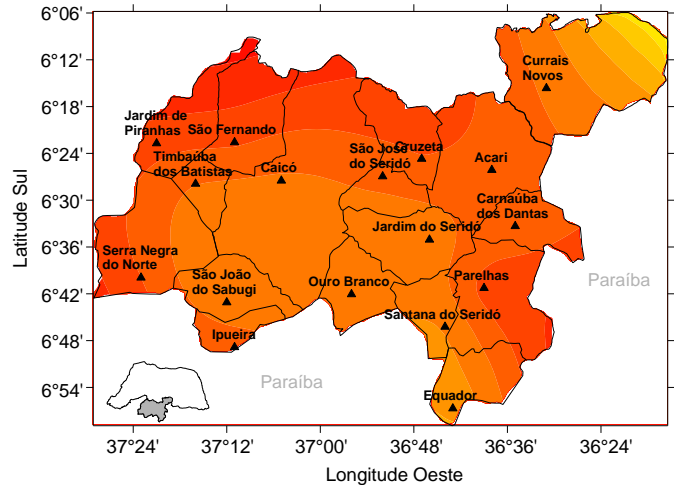

(b)
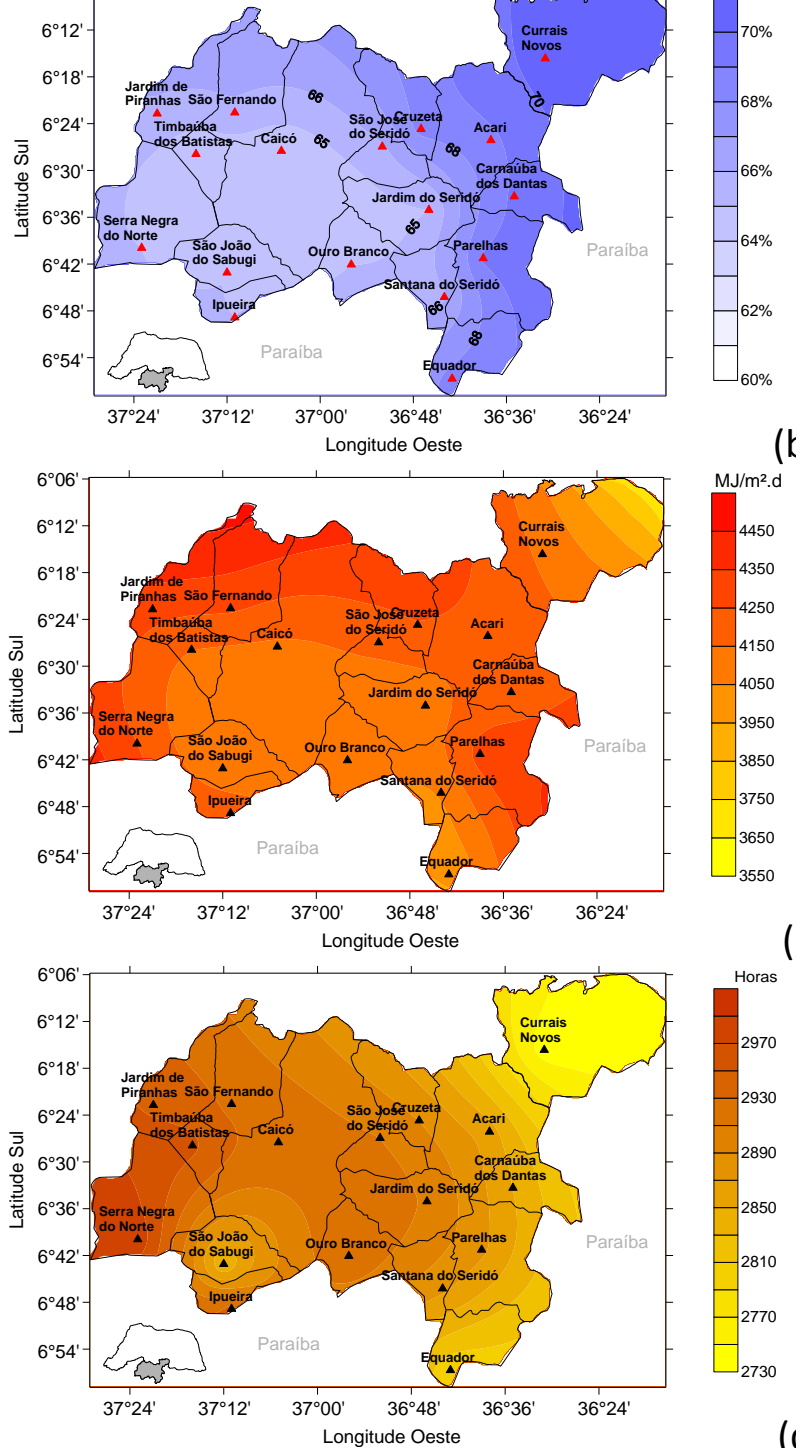

(c)

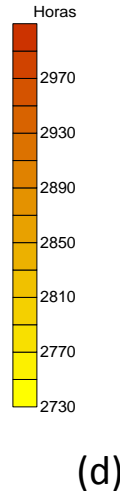

FIGURA 4. Distribuição espacial da média anual de Temperatura do ar (a) e Umidade Relativa do ar (b), e o total anual do Saldo de Radiação (c) e Insolação (d).

A Tabela 1 mostra a média anual da temperatura do ar, umidade relativa e déficit de saturação, além do total anual da precipitação e insolação dos municípios da microrregião do Seridó. Além disso, os valores obtidos pelo modelo complementar de Morton, como o total anual de ETR, ETP e RN para cada munícipio citado. Verificou-se que os valores mais elevados de ETP 
estiveram nas localidades do Seridó Ocidental, tal como, Caicó (com 2.551,3mm), cujos osvalores combinam com a temperatura, umidade, déficit de saturação, saldo de radiação e insolação.

TABELA 1. Média Anual da de temperatura do ar (T), Umidade relativa do ar (UR), déficit de saturação de vapor

$(\Delta e)$ e o total anual de evapotranspiração real de área (ETR), evapotranspiração potencial (ETP), precipitação (PRP), saldo de radiação solar (RN) e insolação (INS) dos municípios da microrregião do Seridó.

\begin{tabular}{|c|c|c|c|c|c|c|c|c|}
\hline \multirow{2}{*}{ Município } & \multicolumn{3}{|c|}{ Média Anual } & \multicolumn{5}{|c|}{ Total Anual } \\
\hline & $\begin{array}{c}\mathrm{T} \\
\left({ }^{\circ} \mathrm{C}\right)\end{array}$ & $\begin{array}{l}\text { UR } \\
(\%)\end{array}$ & $\begin{array}{c}\Delta \mathrm{e} \\
(\mathrm{mb})\end{array}$ & $\begin{array}{c}\text { ETR } \\
(\mathrm{mm})\end{array}$ & $\begin{array}{l}\text { ETP } \\
(\mathrm{mm})\end{array}$ & $\begin{array}{l}\text { PRP } \\
(\mathrm{mm})\end{array}$ & $\begin{array}{c}\mathrm{RN} \\
\left(\mathrm{MJ} \cdot \mathrm{m}^{-2} \cdot \mathrm{d}^{-1}\right)\end{array}$ & $\begin{array}{l}\text { INS } \\
\text { (hrs) }\end{array}$ \\
\hline Acari & 25,2 & 68,8 & 10,1 & $1.270,0$ & $2.325,9$ & 492,0 & $4.206,4$ & $2.860,0$ \\
\hline Caicó & 26,5 & 64,2 & 12,5 & $1.111,4$ & $2.551,3$ & 666,0 & $4.135,1$ & $2.925,0$ \\
\hline Carnaúba dos Dantas & 25,0 & 69,2 & 9,8 & $1.277,0$ & $2.296,5$ & 621,0 & $4.192,3$ & $2.850,0$ \\
\hline Cruzeta & 25,7 & 68,3 & 10,5 & $1.271,9$ & $2.378,8$ & 583,0 & $4.243,6$ & $2.890,0$ \\
\hline Currais Novos & 24,6 & 70,4 & 9,1 & $1.291,1$ & $2.207,4$ & 444,0 & $4.134,6$ & $2.740,0$ \\
\hline Equador & 23,1 & 68,3 & 9,0 & $1.175,6$ & $2.184,6$ & 400,0 & $3.984,4$ & $2.795,0$ \\
\hline Ipueira & 26,2 & 65,0 & 12,0 & $1.166,0$ & $2.520,4$ & 805,0 & $4.204,9$ & $2.936,0$ \\
\hline Jardim de Piranhas & 26,9 & 65,8 & 12,2 & $1.223,6$ & $2.549,7$ & 744,0 & $4.292,9$ & $2.945,0$ \\
\hline Jardim do Seridó & 25,7 & 65,0 & 11,6 & $1.124,4$ & $2.463,4$ & 570,0 & $4.104,3$ & $2.907,5$ \\
\hline Ouro Branco & 25,9 & 65,0 & 11,8 & $1.131,7$ & $2.486,6$ & 568,0 & $4.128,9$ & $2.925,0$ \\
\hline Parelhas & 25,4 & 69,2 & 10,0 & $1.312,6$ & $2.338,3$ & 563,0 & $4.276,9$ & $2.875,0$ \\
\hline Santana do Seridó & 24,9 & 65,8 & 10,8 & $1.131,8$ & $2.385,0$ & 723,0 & $4.064,3$ & $2.875,0$ \\
\hline São Fernando & 26,7 & 65,8 & 12,0 & $1.210,6$ & $2.532,3$ & 701,0 & $4.264,3$ & $2.925,0$ \\
\hline São João do Sabugi & 26,4 & 65,0 & 12,1 & $1.123,6$ & $2.495,8$ & 632,0 & $4.093,9$ & $2.830,0$ \\
\hline São José do Seridó & 25,9 & 65,8 & 11,5 & $1.176,2$ & $2.470,5$ & 578,0 & $4.180,2$ & $2.910,0$ \\
\hline Serra Negra do Norte & 26,7 & 65,0 & 12,4 & $1.185,5$ & $2.559,4$ & 742,0 & $4.253,2$ & $2.985,0$ \\
\hline Timbaúba dos Batistas & 26,5 & 64,2 & 12,5 & $1.117,5$ & $2.561,3$ & 665,0 & $4.154,3$ & $2.955,0$ \\
\hline
\end{tabular}

\section{CONCLUSÕES}

O presente estudo procurou mostrar a distribuição dos potenciais evapotranspirométricos sobre a microrregião do Seridó através do Modelo de relação complementar de Morton,o qual foi usado para gerar as evapotranspirações real de área e potencial. Como a precipitação em toda a região é baixaemrelação aos valores de evapotranspiração, a ETR responde a essa baixa, ficando bem abaixo da ETP. Dessa forma, tem-se que a ETR foisuperior ao extremo norte e sul e baixa na porção central do Seridó.

Pode-se concluir que durante o ano a disponibilidade de energia seja a mais importante no processo de evapotranspiração do que a precipitação sobre a microrregião, sendo assim, o Modelo se torna adequado para avaliar a baixa na precipitação.

\section{AGRADECIMENTOS}

Os autores agradecem ao Programa de Pós-Graduação em Ciências Climáticas ao Laboratório de Recursos Hídricos e Saneamento Ambiental e a CAPES pelo apoio a esta pesquisa. 


\section{REFERÊNCIAS BIBLIOGRÁFICAS}

1. BEZERRA JUNIOR, J. G.O.; SILVA, N. M. Caracterização Geoambiental Da Microrregião Do Seridó Oriental Do Rio Grande Do Norte. RevistaHolos, Ano 23, Vol. 2. 2007.

2. BOUCHET, R.J. Evapotranspiration Réelleetpotentielle, signification climatique. In: International Association of Scientific Hydrology Symposium, 62., 1963, Berkeley, Anais...p.134-142.

3. CAVALCANTI, E.P.; SILVA, V.P.R.; SOUSA, F.A.S. Programa computacional para a estimativa da temperatura do ar para a Região Nordeste do Brasil. Revista Brasileira de Engenharia Agrícola e Ambiental, Campina Grande, PB, v.10, n.1, p.140-147, 2006.

4. GOSSON, P. C. R. Avaliação de métodos de balanço de energia para determinação da evaporação em lago na região semi-árida do RN. Dissertação de mestrado. Universidade Federal do Rio Grande do Norte. Natal (RN), 2005.

5. ISAIAS, E. M. B. I.; ISAIA, T.; VERSLYPE, C.; GARIGLIO, M. A. Avaliação do estoque lenheiro do Estado do Rio Grande do Norte - 1a etapa: Estratificação e mapeamento da vegetação nativa lenhosa através de composições coloridas do TM Landsat. PNUD/FAO-IBAMA. Nota técnica. N. 4, 29p, 1992.

6. JESUS, E. S.; SCHMIDT, D. M.; MATTOS, A.; GOMES JESUS, N. V. Estimativa da Evapotranspiração de alguns Municípios da Região do Seridó-RN. Congresso Brasileiro de Meteorologia, Gramado-RS. 2012. Anais do XVII CBMET.

7. JESUS, E.S. Avaliação Mensal da Evapotranspiração no Estado do Rio Grande do Sul utilizando o Modelo Complementar de Morton. Dissertação de mestrado. Universidade Federal de Pelotas. 2004. 89p.

8. JESUS, E.S., ASSIS, S.V. Evapotranspiração Mensal da Região da Campanha do Estado do Rio Grande do Sul. Congresso Brasileiro de Meteorologia, Fortaleza-CE. 2004. Anais do XIII CBMET.

9. MENDONÇA, E. A.; DANTAS, R. T. Estimativa da Evapotranspiração de Referência no município de Capim, PB. Revista Brasileira de Engenharia Agrícola e Ambiental, v. 14, n. 2, p. 196-202, 2010.

10. MORTON, F.I. Operation estimatives of areal evapotranspiration and their significance to the science and practice of hydrology. JournalofHydrology, v.66,p.1-76.1983.

11. MORTON, F.I., RICARD, F., FOGARASI, S. Operational estimates of areal evapotranspiration and lake evaporation - Program WREVAP. National Hydrology Research Institute. Inlan Waters Directorate. Ottawa, Canada, NHRI PAPER, n.24, 1985.

12. MOTA, F. S. Meteorologia Agrícola, São Paulo, NOBEL, 1977.

13. PEREIRA, A. R.; VILLA NOVA, N. A.; SEDIYAMA, G. C. Evapotranspiração. Piracicaba: FEALQ, 183 p. 1997.

14. PRIESTLEY CHB; TAYLOR RJ. On the assessment of surface heat flux and evapotranspiration using large scale parameters. Mon Weather Rev 100:81-92.1972.

15. ROSS, Jurandir L. Sanches. Geografia do Brasil. São Paulo: Edusp, p.57, p.63,p.103-105. 2003.

16. SANTOS, A. S.; MATTOS, A.; LOPO, A. B.; MEDEIROS, F. C.; BRISTOT, G.; PINHEIRO, J. U. Estimativa do Balanço Hídrico Climático para a Microrregião do Seridó - Estado do Rio Grande do Norte. Congresso Brasileiro de Meteorologia, Belém-PA. 2010. Anais do XVI CBMET. 